\title{
Deficiencies of sodium and iodine in grazing sheep in northern China
}

\author{
DG Masters 1, JR Lindsay 1, SX Yu 2, DX Lu 3, S Harali 4, CL Kang 5 \\ 'CSIRO Division of Animal Production, Private Bag, PO, Wembley, WA 6014 Australia ; 2Institute \\ of Animal Science, Chinese Academy of Agricultural Science, Haidian, Beijing; 3Inner Mongolia Academy \\ of Animal Science, The Western Suburbs of Huhehot City, Inner Mongolia Autonomous Region; ${ }^{4}$ Xinjiang \\ Academy of Animal Science, Urumqi, Xinjiang Uygur Autonomous Region ; 5 Lanzhou Institute of Traditional \\ Veterinary Medicine, Chinese Academy of Agricultural Science, Xiaoxihu, Lanzhou, Gansu, China
}

An examination of the mineral status of grazing sheep at 3 sites in northern China has provided evidence of inadequate mineral intakes (Masters et al, 1993, Asian Austral J Anim Sci, $6,99-113$ ). Because of the small number of sites used in these studies, it is necessary to be cautious in generalising from the results. Consequently, the aim of the study reported here was to provide more extensive data by evaluating the mineral status of sheep on 15 farms in northern China.

Five farms were selected in each of the Xinjiang Uygur and Inner Mongolia Autonomous Regions, 3 in Gansu Province and 2 in Qinghai Province. On each tarm, 20 breeding ewes were sampled at 4 times during the year, and plasma, parotid saliva, faeces and pasture collected. Samples of milk were collected once. These samples were analysed for a range of elements ; results are presented here for sodium and potassium in saliva and iodine in milk.

The table shows the range of seasonal means. Many of the sheep had a sodium : potassium (Na:K) ratio in saliva indicative of an inadequate intake of sodium (10:1), the Na:K ratio was below $10: 1$ on 6 of the 15 farms in summer. Sheep on 3 farms produced milk with an iodine level below or close to the level that indicates an inadequate iodine intake $(76 \mu \mathrm{g} / \mathrm{l})$. It is concluded that production from grazing sheep in some regions of China may be depressed by a lack of sodium and/or iodine at some times of the year.

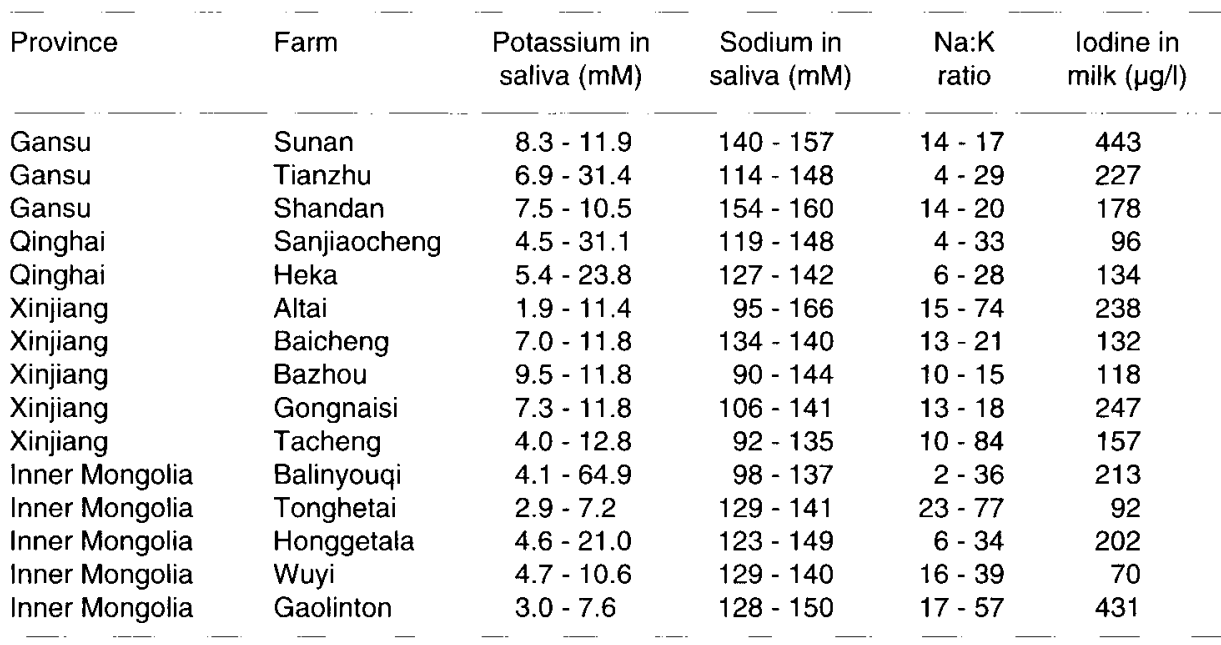

This research was supported by the Australian Centre for International Agricultural Research and the Ministry of Agriculture, China. 